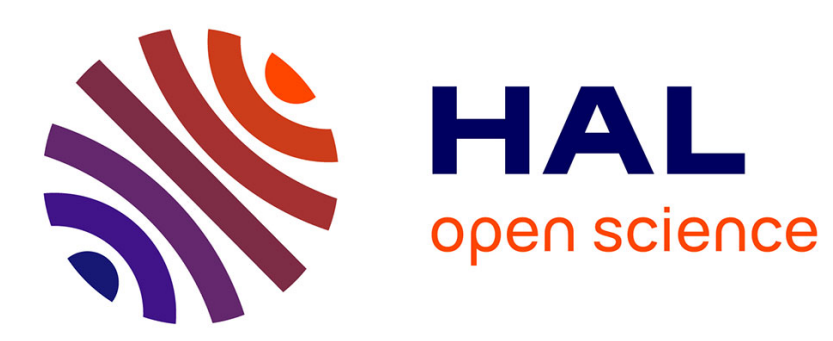

\title{
Experimental and theoretical evaluation of magnetic coupling in organometallic radicals: the eloquent case of face-to-face $\mathrm{CpCp}$ interactions
}

Marc Fourmigué, Thomas Cauchy, Mitsushiro Nomura

\section{- To cite this version:}

Marc Fourmigué, Thomas Cauchy, Mitsushiro Nomura. Experimental and theoretical evaluation of magnetic coupling in organometallic radicals: the eloquent case of face-to-face $\mathrm{CpCp}$ interactions. CrystEngComm, 2009, 11 (8), pp.1491-1501. 10.1039/b823200h . hal-00405775

\section{HAL Id: hal-00405775 \\ https://hal.science/hal-00405775}

Submitted on 13 Sep 2013

HAL is a multi-disciplinary open access archive for the deposit and dissemination of scientific research documents, whether they are published or not. The documents may come from teaching and research institutions in France or abroad, or from public or private research centers.
L'archive ouverte pluridisciplinaire HAL, est destinée au dépôt et à la diffusion de documents scientifiques de niveau recherche, publiés ou non, émanant des établissements d'enseignement et de recherche français ou étrangers, des laboratoires publics ou privés. 

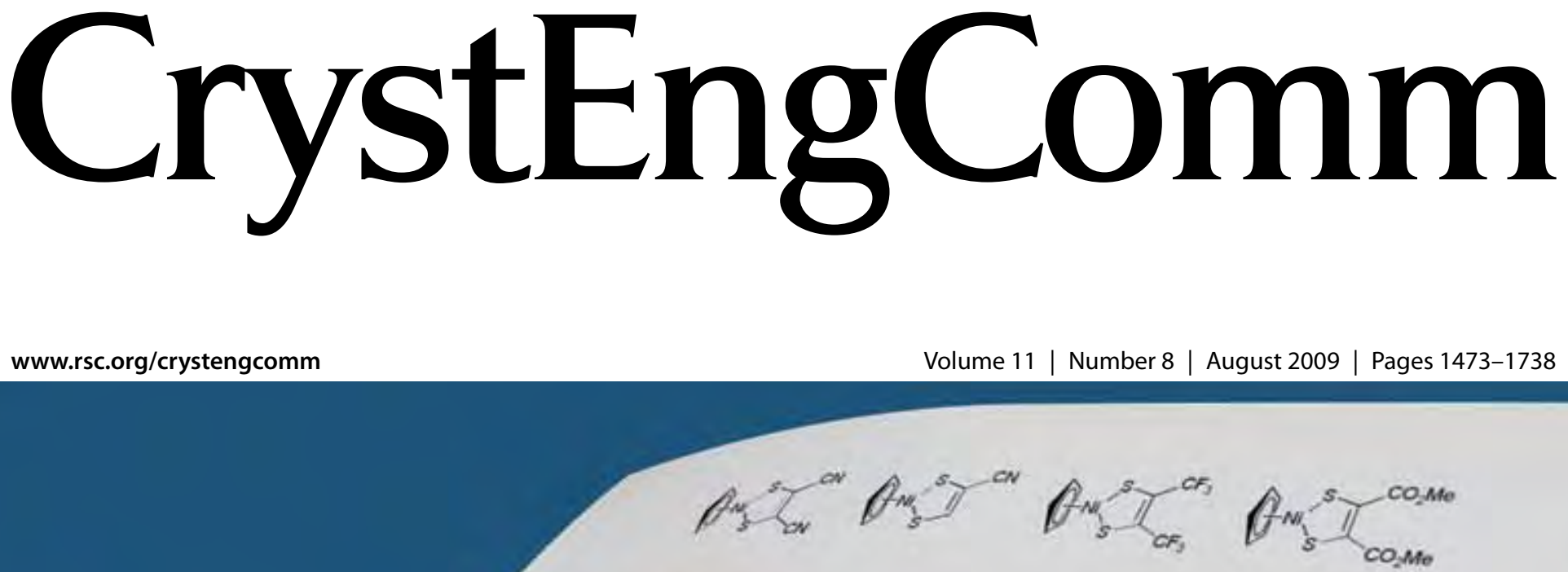


\title{
Experimental and theoretical evaluation of magnetic coupling in organometallic radicals: the eloquent case of face-to-face $\mathrm{Cp} \cdots \mathrm{Cp}$ interactions
}

\author{
Marc Fourmigué, $^{* a}$ Thomas Cauchy $^{a}$ and Mitsushiro Nomura ${ }^{a b}$ \\ DOI: $10.1039 / \mathrm{b} 823200 \mathrm{~h}$
}

The solid state magnetic properties of an extensive series of neutral radical $(S=1 / 2)$ complexes associating cyclopentadienyl $(\mathrm{Cp})$ and dithiolene ligands and formulated as $[\mathrm{CpNi} \text { (dithiolene) }]^{\circ}$, are successfully rationalized through a combination of structural analysis of the crystal structures and broken symmetry DFT calculations. The highly delocalized spin density of these complexes allows for strong antiferromagnetic interactions between radical species, which involve not only short intermolecular $S \cdots S$ contacts but also $S \cdots C p$ and $C p \cdots C p$ contacts, demonstrating that the cyclopentadienyl moiety can effectively act as a noninnocent ligand in metal complexes where it bears a sizeable fraction of the spin density, for example, up to $20 \%$ in these $[\mathrm{CpNi(dithiolene)]}$ ' neutral radical complexes.

\section{Introduction}

Since the electronic properties of magnetic solids, beyond the Curie-type behaviour of non-interacting spins, result

${ }^{a}$ Sciences Chimiques de Rennes, Université de Rennes 1, UMR CNRS 6226, Rennes, 35042, France. E-mail: marc.fourmigue@univ-rennes1. fr; Web: http://scienceschimiques.univ-rennes1. fr/macse; Fax: (+33) 223236732

${ }^{b}$ Department of Materials and Life Sciences, Faculty of Science and Technology, Sophia University, Kioi-cho 7-1, Chiyoda-ku, Tokyo, 102-8554, Japan essentially from exchange interactions between paramagnetic centres, the control of their solid state organisation is crucial to understanding and eventually anticipating these properties. In that respect, crystal engineering strategies are not only legitimate but strongly needed if one works with molecular compounds. The only limitation to these combined approaches in the domain of molecular magnetism lies in the different energy ranges which control the solid state organisation on the one hand, and the magnetic behaviour on the other hand.
For example, the energy of a normal hydrogen bond amounts to 5 to $10 \mathrm{kcal}$ $\mathrm{mol}^{-1}$ for water or carboxylic acid dimers, respectively, ${ }^{1}$ that is, from 1750 to 3500 $\mathrm{cm}^{-1}$. For comparison, within the prototypical copper acetate dimer, ${ }^{2}$ the singlet state is stabilised relatively to the triplet state by a ten times smaller energy $(\approx 300$ $\mathrm{cm}^{-1}$ ), albeit such a magnetic interaction will be considered as a strong one in molecular magnetism. One can therefore anticipate that apparently negligible structural modifications will induce important changes in the magnetic

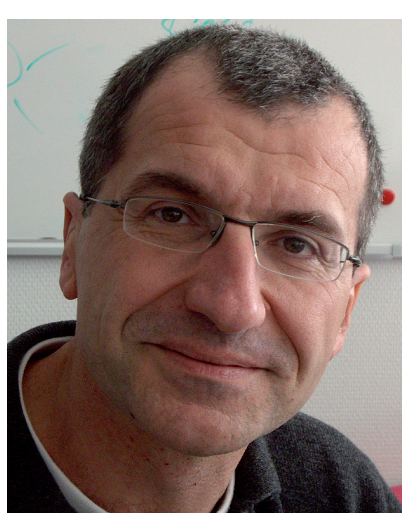

Marc Fourmigué earned his PhD (1988) under the supervision of Klaus Bechgaard and Patrick Batail and got his CNRS position (1990) in Orsay (Laboratoire de Physique de Solides). After 7 years at the IMN Jean Rouxel, Nantes, he moved to Angers in CIMMA Laboratory (2002), and is now at Rennes University (since 2006). His research interests range from low-dimensional molecular conductors to the chemistry of dithiolene complexes. He has received the Coordination Chemistry Award of the French Chemical Society (1997) and the Paul Pascal Award of the French Academy of Sciences (2007).

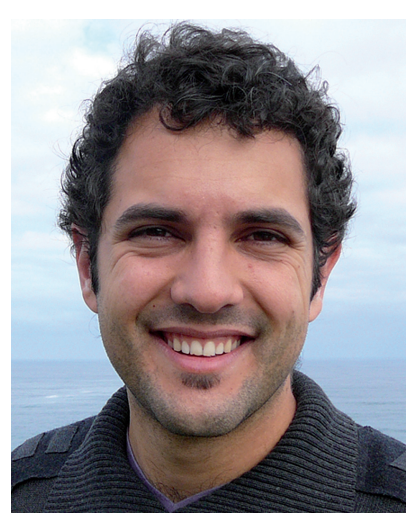

Thomas Cauchy finished his $P h D$ in 2007 under the supervision of Eliseo Ruiz in the Universitat de Barcelona (estructura electronica grup) and Marc Fourmigué in the Université d'Angers (CIMMA Laboratory). He is currently on a Postdoc position in the "Chimie Théorique Inorganique" group of the University of Rennes Chemistry Department "Sciences Chimiques de Rennes". His research is mainly focused on the theoretical evaluation of magnetic coupling constants in inorganic and organometallic compounds. 
response and that a precise control of crystal engineering strategies is needed to really anticipate the magnetic behaviour of molecular magnetic materials (MMM).

Historically, several approaches have been considered for the elaboration of such materials. One of them has concentrated on purely organic radicals such as triarylmethyl, ${ }^{3}$ nitronyles, nitronylnitroxydes, ${ }^{4}$ or verdazyl $^{5}$ species, characterised by weak but sometimes ferromagnetic interactions. ${ }^{6,7}$ Attempts to control their solid state organisation have been described, relying on hydrogen bonding, ${ }^{4}$ halogen bonding ${ }^{8}$ or chirality ${ }^{9}$ and organic ferromagnets were also reported. ${ }^{10,11}$

Another approach towards MMM involves the coordination and inorganic chemistry of paramagnetic metal centres, as beautifully illustrated by the first rationally synthesised ferromagnetic dinuclear compound, a $\mathrm{Cu}^{\mathrm{II}} / \mathrm{V}^{\mathrm{IV}}=\mathrm{O}$ complex, ${ }^{12,13}$ ferrimagnetic chains controlled by hydrogen bonding, ${ }^{14}$ or the Prussian Blue analogues with Curie temperatures exceeding $300 \mathrm{~K}^{15,16}$ The recent developments of this field toward single molecule magnets (SMM), ${ }^{17,18}$ and single chain magnets $(\mathrm{SCM})^{\mathbf{1 9 , 2 0}}$ also make use of this approach, and are based on weak magnetic interactions between metallic centres with well defined oxidation states, through oxo, oxalato, carboxylato, cyano or azido bridges. ${ }^{21}$

The combination of both organic and inorganic approaches, ${ }^{22}$ using the organic radicals as ligands to coordinate metal centres, affords, for example, the very first isolated SCM where nitronylnitroxyde radicals coordinate $\mathrm{M}(\mathrm{hfac})_{2}$ species through their oxygen atoms. ${ }^{23,24}$ This approach was also extended to radical anion species such as $\mathrm{TCNQ}^{-}$or $\mathrm{TCNE}^{-}$whose metallic salts-coordinated through the nitrile substituentsexhibit high Curie temperatures. ${ }^{25,26}$

Beside these three approaches, paramagnetic organometallic derivatives were also considered, as for example in $\left(\mathrm{Cp}^{*}{ }_{2} \mathrm{Fe}\right)(\mathrm{TCNE})$, the first molecular magnet described by Miller, ${ }^{27,28}$ and characterized by a face-to-face overlap between the $\mathrm{Cp}^{*}$ and TCNE moieties. In these series, the magnetic properties are now directly related to this overlap and to the nature of the spin density on the $\mathrm{Cp}$ ring. While the ferricinium salt exhibits a ferromagnetic behaviour attributed to a weak negative spin density on the $\mathrm{Cp},{ }^{29}$ the analogous nickelocenium cation is characterised by a large positive spin density $^{30}$ on the $\mathrm{Cp}$ which favours a direct antiferromagnetic interaction with the $\mathrm{TCNE}^{-}$radical anion. ${ }^{31}$ Such organometallic radical species, particularly if they involve non-innocent ligands, can therefore exhibit a highly delocalized spin density. Accordingly, strong intermolecular magnetic interactions can be anticipated, provided that direct overlaps between the radical species are favoured.

For simple cases, or as a first approximation, hints about the nature of the magnetic interaction can be provided by semi-empirical models. Following the basic rules of Goodenough ${ }^{32}$ and Kanamori $^{33}$ or the most developed version of Kahn-Briat, ${ }^{34}$ strong overlap between the wave functions of the unpaired electrons correspond to a strong antiferromagnetic interaction. ${ }^{35}$ On the other hand, a ferromagnetic interaction is expected between unpaired electrons based on orthogonal

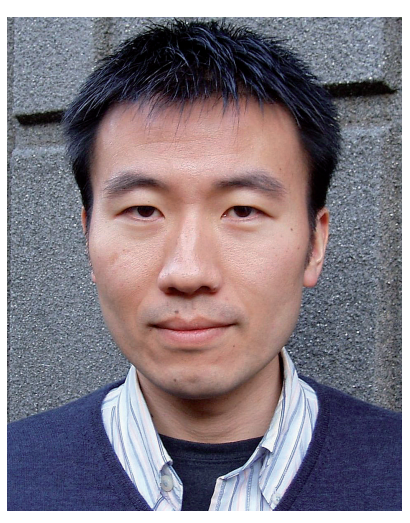

Mitsushiro Nomura received his B.Sc. in 1999, M.Sc. in 2001, and Ph.D. degrees in 2004 from Sophia University (Tokyo, Japan) under the supervision of Prof. Masatsugu Kajitani. He joined the CIMMA laboratory in Angers (France) as a postdoctoral fellow in 2005 and moved to Rennes in 2006 with Marc Fourmigué. After a period spent at the University of Rochester (USA) in 2007, he has been working at Sophia University since 2008. His current research interests are focused on the syntheses, structures and electrochemistry of heteroleptic [CpM(dithiolene)] complexes ( $M=\mathrm{Co}, \mathrm{Ni}$ ) and the comparison of their chemical and physical properties.

orbitals. ${ }^{12}$ Such tools are still very useful to rationally design new magnetic compounds. However, when there are many paramagnetic centres, when the orbitals of the unpaired electron are unknown or simply when a quantitative approach is needed, theoretical calculations of the exchange interaction paths can be an answer even if the modelisation of magnetic properties still remains today one of the hardest theoretical and computational challenges. The experimental determination of the temperature dependence of the magnetic susceptibility does not give much molecular insight on the magnetic properties as it indicates only the global population of the different spin states. If many exchange interactions take place in the system, there will be too many variables to simply fit the experimental data, and, in many cases it will be hazardous, if not impossible, to predict which intermolecular contacts are responsible for the different spin states energies. Also, the energy differences between those spin states are usually very small when compared with the so called "weak" supramolecular interactions which held molecules together in a solid. Therefore, the computation of the exchange interactions requires high precision calculations.

Besides this technical difficulty, there is also an inherent problem associated with the computation of exchange interactions as all the open shell spin states, other than the high spin one, are multi-configurational by nature, i.e. described by a combination of spin distributions, and should be calculated by adapted methods. When the system is small, one can use post Hartree-Fock treatments like the difference dedicated configuration interaction approach (DDCI), developed by Malrieu, to compute the fundamental spin states and all pertinent excited states, ${ }^{36}$ which also gives useful informations on the relative weight of the different configurations. However, such approach has a huge computational cost. For systems with many unpaired electrons, the only affordable method is based on the broken symmetry strategy developed by Noodleman. ${ }^{37}$ In this approach, the exchange interactions are derived from a system of mono-configurational spin distribution calculations. Ruiz has shown that this approach, used in the density functional theory framework with 
a hybrid functional like B3LYP, ${ }^{38}$ can quantitatively reproduce the exchange interactions of many systems, even with many paramagnetic centres. ${ }^{39,40}$ The question then arises if these theoretical approaches used up to now for evaluating in a quantitative way the exchange coupling interactions between metallic spins essentially localized in d orbitals, can also be applied to molecular organic or organometallic systems in which the spin density is now strongly delocalized. In the following, we will show that such DFT calculations are effectively a very useful, cheap and reliable way to investigate the strength of intermolecular magnetic interactions in molecular magnetic materials.

To illustrate this interplay between the solid state structures adopted by highly delocalised organometallic radical species and their magnetic behaviour, we have chosen an extended series of neutral radical organometallic dithiolene complexes, associating both a cyclopentadienyl and a non-innocent dithiolate ligand and formulated as [ $\mathrm{CpNi}$ (dithiolene) $]^{\cdot{ }^{41}} \mathrm{We}$ have recently developed efficient synthetic methods to prepare these formally $\mathrm{Ni}(\mathrm{III}), 17-$-electron, $\mathrm{S}=1 / 2$ complexes, ${ }^{42,43}$ and more than 20 of these complexes have been reported by now, together with their solid state structural and magnetic properties, allowing for a fruitful comparison between the different overlap patterns they adopt in the solid state, and their magnetic behaviour. Each radical complex is characterized by a spin density distribution, and in the solid state, by numerous short intermolecular contacts. We present here a strategy aimed at identifying unambiguously the pertinent interactions which are responsible for their magnetic behaviour in the solid state. We will particularly demonstrate that not only short intermolecular $\mathrm{S} \cdots \mathrm{S}$ contacts but also $\mathrm{S} \cdots \mathrm{Cp}$ and most surprising $\mathrm{Cp} \cdots \mathrm{Cp}$ face-to-face contacts can contribute to the observed magnetic interactions.

\section{Homo- and heteroleptic dithiolene complexes}

Dithiolene complexes ${ }^{44,45}$ are based on the non-innocent ethylene-1,2-dithiolate $\mathrm{R}_{2} \mathrm{C}_{2} \mathrm{~S}_{2}{ }^{2-}$ (dt) ligand, substituted with various $\mathrm{R}$ groups (Scheme 1), electronwithdrawing substituents such as $-\mathrm{CN}$ or

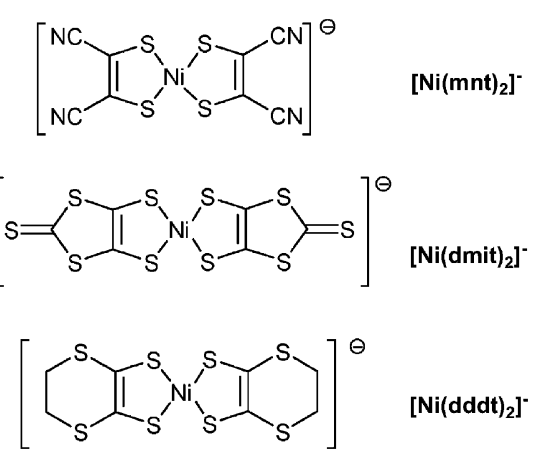

Scheme 1 Examples of square planar, homoleptic, radical anion, nickel dithiolene complexes.

$\mathrm{CF}_{3}$, thioalkyl groups as in dmit (1,3-dithiole-2-thione-4,5-dithiolato) ${ }^{46}$ or dddt (5,6-dihydro-1,4-dithiine-2,3-dithiolato), fused rings as in bdt (1,2-benzenedithiolato), electron-releasing groups such $-\mathrm{Me}$ or $-\mathrm{Ph}$. Square planar metal complexes of the $\mathrm{Ni}$ triad exhibit a rich electrochemistry, ${ }^{47}$ with $\left[\mathrm{M}(\mathrm{dt})_{2}\right]^{\mathrm{n}}$ complexes known in four different oxidation states with $n=$ $-2,-1,0$ or +1 , and the $\mathrm{S}=1 / 2$ monoanionic $\left[\mathrm{Ni}(\mathrm{dt})_{2}\right]^{-\cdot}$ radical complexes such as $\left[\mathrm{Ni}(\mathrm{mnt})_{2}\right]^{-}$(Scheme 1) have been extensively investigated for their magnetic properties, ${ }^{48}$ in solution as well as in the solid state. ${ }^{46 b, 49}$

Because of the planarity of the system, these complexes most often stack on top of each other. Combined with the $\pi$ character of their frontier orbitals, this leads to a strong direct antiferromagnetic interaction between the radical species, either within isolated dyads or in extended uniform or alternated chains. ${ }^{48}$ On the other hand, these radical complexes,

The (formally) $d^{1}$ complexes:

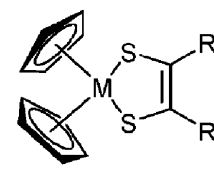

$\left[C p_{2} M(d t)\right]^{0}, M=V, N b$ $\left[\mathrm{Cp}_{2} \mathrm{M}(\mathrm{dt})\right]^{+}, \mathrm{M}=\mathrm{Mo}, \mathrm{W}$<smiles></smiles>

$\left[\mathrm{CpM}\left(\mathrm{dtt}_{2}\right]^{0}, \mathrm{M}=\mathrm{Mo}, \mathrm{W}\right.$

The (formally) $d^{7}$ complexes:<smiles>[R]C1=C([R])SN(n2cccc2)S1</smiles>

$[\mathrm{CpNi}(\mathrm{dt})]^{0}$ particularly when substituted with sulfur rich groups as in $\left[\mathrm{Ni}(\mathrm{dmit})_{2}\right]^{-}$or $\left[\mathrm{Ni}(\mathrm{dddt})_{2}\right]^{-}$(Scheme 1) can also crystallise into mixed-valence stacks or slabs where the strong intermolecular antiferromagnetic interactions lead to the formation of partially occupied conduction bands with a sizeable dispersion, allowing for the observation of metallic and even superconducting behaviour. ${ }^{49,50}$ As the frontier orbitals (HOMO and LUMO) in these complexes are strongly delocalised on the dithiolene ligands, and particularly on the sulfur atoms, ${ }^{51}$ the identification of "short" $\mathrm{S} \cdots \mathrm{S}$ intermolecular contacts offers a preliminary analysis of pertinent intermolecular interactions. For such conducting materials, tight-binding extended Hückel (EH) calculations were systematically used to calculate overlap interaction energies $(\beta)$ and the associated band structures. ${ }^{52,53}$ If we are now in the presence of insulating salts, these EH calculations can still be

Scheme 2 Examples of heteroleptic paramagnetic dithiolene complexes and their geometry.
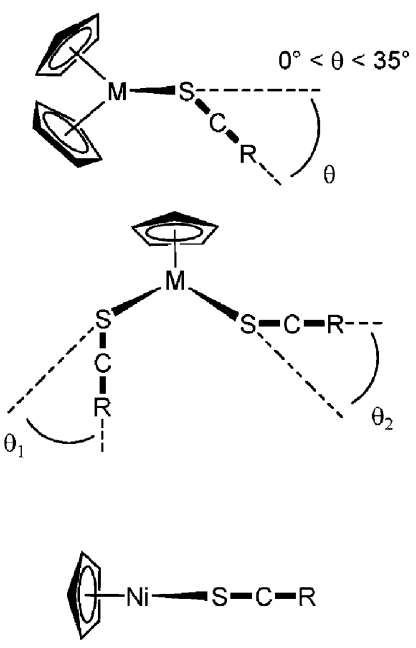
used to determine $\beta$ values related to the antiferromagnetic interactions between radical species. ${ }^{54}$ Indeed, in a Hubbard model, ${ }^{55}$ the exchange integral $J$ between radicals is related to the $\beta^{2} / U$ ratio, where $\beta$ is the above-mentioned interaction energy between SOMOs and $U$ the energy difference between the (singlet or triplet) ground state configuration and a charge transfer configuration. ${ }^{56}$ This approach to evaluate $J$ values in insulating paramagnetic complexes finds however rapidly its limitations when the interactions between radical species are weak.

It is particularly the case in various series of heteroleptic dithiolene complexes associating cyclopentadienyl rings and dithiolene ligands (Scheme 2), of general formula $\left[\mathrm{Cp}_{n} \mathrm{M}(\mathrm{dt})_{m}\right]{ }^{57}$ Among them, radical paramagnetic species are essentially found with, (i) the group 6 metal centres (Mo, W) with a formal $\mathrm{d}^{1}$ structure in $\left[\mathrm{Cp}_{2} \mathrm{M}(\mathrm{dt})\right]^{+}$or $\left[\mathrm{CpM}(\mathrm{dt})_{2}\right]^{\cdot}$ species, (ii) $[\mathrm{CpNi}(\mathrm{dt})]^{\bullet}$ complexes which are formally $\mathrm{d}^{7} \mathrm{Ni}$ (III) species. ${ }^{58}$

These heteroleptic radical complexes are not planar anymore like their homoleptic analogues, and therefore can not easily interact in the solid state through the classical stacking. As a consequence, the overlap interactions between radical species are much weaker and therefore more sensitive to the details of the spin density distribution within the radical on the one hand, and to the variety of intermolecular contacts which settle in the crystalline state on the other hand. In these salts, the $J$ values determined experimentally from magnetic measurements have been related in some cases to the calculated $(\mathrm{EH}) \quad \beta$ values, ${ }^{59,60}$ providing only a qualitative agreement. Furthermore, the series of $\mathrm{d}^{1}$ Mo and $\mathrm{W}$ $\left[\mathrm{Cp}_{2} \mathrm{M}(\mathrm{dt})\right]^{+}$or $\left[\mathrm{CpM}(\mathrm{dt})_{2}\right]^{\bullet}$ are characterized by strong distortions of the $\mathrm{MS}_{2} \mathrm{C}_{2}$ metallacycles (Scheme 2 right). ${ }^{59,60}$ The variable folding along the $\mathrm{S}-\mathrm{S}$ hinge observed in these complexes depends on the counter-ions and the details of the solid state structures. As a consequence, the SOMO of a given complex is different for every folding angle, introducing an added element of complexity in attempts to estimate the spin density distribution and extent of magnetic interactions. ${ }^{58} \mathrm{We}$ will therefore concentrate in the following on the formally $\mathrm{Ni}(\mathrm{III})$ [CpNi(dt) $^{*}$ complexes. They are particularly attractive for several reasons: anion and reversibly oxidized to the formally $\mathrm{d}^{6}$ cation, and are stable in a large electrochemical potential window; they are air stable and well crystallised,

(ii) they all adopt the same molecular geometry with an unfolded metallacycle and with the $\mathrm{Cp}$ ring perpendicular to the dithiolene mean plane,

(iii) since they are neutral and unsolvated in their crystalline forms, the absence of any counter-ion or solvent molecule limits the possible paths of intermolecular interactions to only direct exchange mechanisms,

(iv) the extent of delocalization of the spin density between the $\mathrm{Cp}$, the nickel and the dithiolene moieties was found to depend strongly on the nature of the dithiolene ligand.

They therefore offer a magnificent playground to evaluate the nature and strength of different overlap situations encountered in organometallic solid state chemistry, as revealed below. A large number of such [CpNi(dt) ${ }^{\bullet}$ complexes (Scheme 3) have been prepared so far, differing only in the nature of the substituents on the two carbon atoms of the metallacycle.

As we will see below, they adopt various structural motifs in the solid state, behaviour. In some cases, they exhibit (i) they are reversibly reduced to the $\mathrm{d}^{8}$ associated with characteristic magnetic

structural properties characteristic of homoleptic dithiolene complexes, that is a combination of (i) face-to-face $\pi-\pi$ type and (ii) lateral $\mathrm{S} \cdots \mathrm{S}$ interactions. However, the presence of the cyclopentadienyl ring opens new possibilities, such as (iii) $\mathrm{Cp} \cdots \mathrm{S}$ and (iv) $\mathrm{Cp} \cdots \mathrm{Cp}$ short contacts. In the following, we will describe concomitantly their structural and magnetic properties, according to the four different interaction patterns described above, with an emphasis on the role provided here by the "organometallic" cyclopentadienyl ring on the magnetic properties.

\section{The various solid state and magnetic structures of [CpNi(dithiolene)] complexes}

\section{Face-to-face overlap}

The square-planar $\left[\mathrm{Ni}(\mathrm{dt})_{2}\right]^{1-}$ complexes exhibit a strong tendency to stack on top of each other, either two-by-two in their radical anion state, or into infinite 1-D chains in their partially oxidized conducting salts. ${ }^{49,50,53}$ The steric requirement of the $\mathrm{Cp}$ ring, perpendicular to the dithiolene mean plane, limits in most cases this overlap motif. The examples provided by the solid state structures of, (i) $[\mathrm{CpNi(mnt)]} \mathrm{with} \mathrm{a} \mathrm{flat} \mathrm{dithiolene}$ moiety, ${ }^{42,61}$ (ii) $\left[\mathrm{CpNi}\left(\mathrm{F}_{2} \mathrm{pddt}\right)\right]$ and<smiles>N#CC1=C(C#N)C2=CC=CN(S2)S1</smiles>

CpNi(mnt)

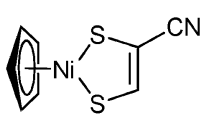

CpNi(adt)<smiles>FC(F)(F)C1=C(C(F)(F)F)N2C=CC=CN2S1</smiles>

CpNi(tfd)<smiles>COC(OC)C1=C(C(C)=O)SN(n2cccc2)S1</smiles>

CpNi(dcmedt)

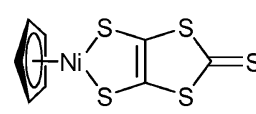

CpNi(dmit)<smiles>c1cnn(N2SC3=C(SCCS3)S2)c1</smiles>

CpNi(dddt)

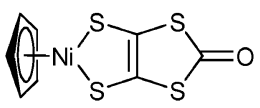

CpNi(dmid)<smiles></smiles>

CpNi(dsdt)<smiles>S=c1sc2c(s1)[Se]N1C=C[C+]1C2</smiles>

CpNi(dsit)<smiles>C1=C[Se]N2[Se]C3=C(SCCS3)C2=C1</smiles>

CpNi(ddds)<smiles>C1=CN2SC(=C1)c1ccccc1S2</smiles>

CpNi(bdt)<smiles>C1=C[Ge]2c3ccccc3[Se]N2C1</smiles>

CpNi(bds)
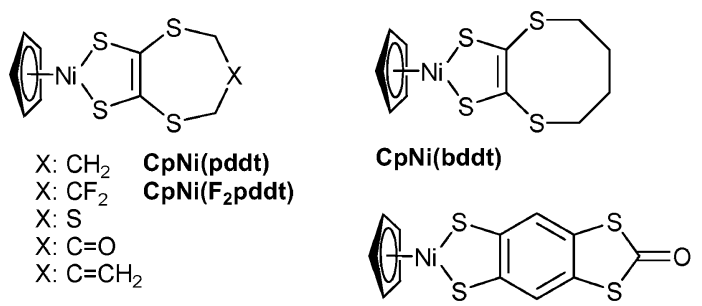<smiles>c1ccc2c(c1)CSC1=C(S2)SN(C2CCC2)S1</smiles>

CpNi(oxddt)

CpNi(bdtodt)

Scheme 3 Different [CpNi(dithiolene)] complexes. 

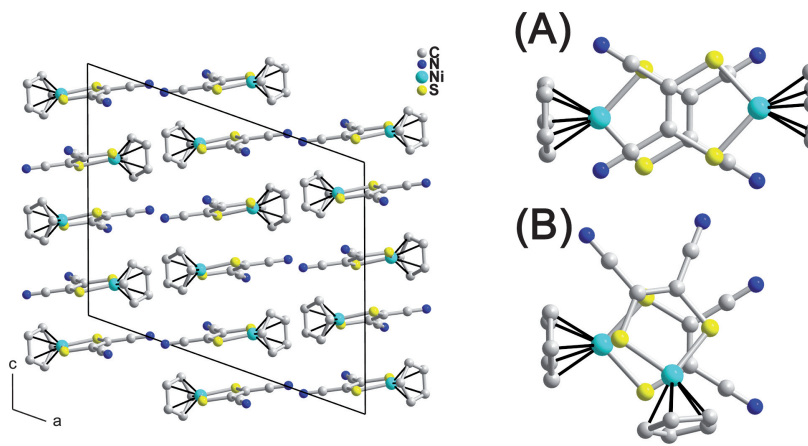

Fig. 1 Left: a view of the chains of [CpNi(mnt)] running vertically along the crystallographic $c$ axis. Right: the two different overlap patterns A and B (see text) within the chains.
[CpNi(oxddt)] with strongly distorted dithiolene moieties on the other hand, ${ }^{62,63}$ illustrate however the different ways in which such a face-to-face overlap can still take place, with its associated singlettriplet magnetic behaviour. As shown in Fig. 1, the radical $[\mathrm{CpNi}(\mathrm{mnt})]$ complexes organize in the solid state into alternated 1-D chains, with two different overlap patterns, noted $\mathrm{A}$ and $\mathrm{B}$ in the following. ${ }^{61}$

Pattern A describes inversion-centred dyads with a short plane-to-plane distance (3.65 $\AA$ ) while pattern B is associated with an apparently less favourable criss-cross overlap of the mnt moieties lying in non-parallel planes, further characterized by a large $\mathrm{Ni} \cdots \mathrm{S}$ distance of $4.34 \AA$. The temperature dependence of the magnetic susceptibility of a powder sample shows a singlet-triplet behaviour and a strong antiferromagnetic interaction $\left(J=-240 \mathrm{~cm}^{-1}\right)$, which indicates that one of the two overlap patterns dominates the magnetic behaviour. In order to discriminate between the two $\mathrm{A}$ and $\mathrm{B}$ possibilities, the exchange coupling constants were calculated by broken symmetry DFT as detailed above, affording $J_{\mathrm{A}}=+2.6 \mathrm{~cm}^{-1}$ and $J_{\mathrm{B}}=-160$

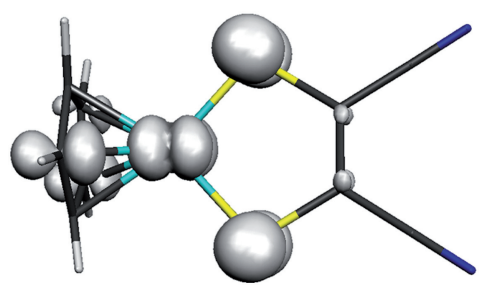

Fig. 2 Spin density distribution in $[\mathrm{CpNi}(\mathrm{mnt})]$. The isodensity surface represented corresponds to a value of $0.005 \mathrm{e}^{-}$ bohr $^{-3}$. $\mathrm{cm}^{-1} \cdot{ }^{64}$ It follows that pattern $\mathrm{B}$ is unambiguously identified as the origin of the strong antiferromagnetic interaction. Observation of the spin density distribution in $[\mathrm{CpNi}(\mathrm{mnt})]$ (Fig. 2) gives a rationale for this apparently surprising behaviour, as the spin density is essentially localised on the sulfur (17\% each) and $\mathrm{Ni}$ atom (43\%), with a sizeable contribution of the $\mathrm{Cp}$ ring $(21 \%)$. Despite the short plane-to-plane distance in the A overlap pattern, $\mathrm{Ni} \cdots \mathrm{S}$ contacts are absent and $\mathrm{S} \cdots \mathrm{S}$ distances exceed 4.27 $\AA$. On the other hand, the two Ni...S contacts in overlap B are clearly at the origin of the strong antiferromagnetic interaction.

As shown in Fig. 3, $\left[\mathrm{CpNi}\left(\mathrm{F}_{2}\right.\right.$ pddt $\left.)\right]$ with its seven-member ring $^{62}$ and [CpNi(oxddt)] with an eight-member ring $^{63}$ offer another alternative to face-to- face overlap due to the strong distortions of the seven- and eight-member rings in the dithiolene moieties which hinders any other inter-dyad intermolecular contacts. Because of the steric requirement of the $\mathrm{Cp}$ moiety, the inter-planar distances are rather large, as also the $\mathrm{Ni} \cdots \mathrm{S}$ and $\mathrm{S} \cdots \mathrm{S}$ intermolecular distances. As a consequence, the singlet-triplet magnetic behaviour observed in both complexes denotes only weak intermolecular interactions, characterized indeed with experimental $J$ values of -29 or $-8 \mathrm{~cm}^{-1}$ for $[\mathrm{CpNi}($ oxddt $)]$ and $\left[\mathrm{CpNi}\left(\mathrm{F}_{2}\right.\right.$ pddt $\left.)\right]$, respectively.

\section{Lateral S $\cdots$ S contacts}

In those situations where the face-to-face overlap of the dithiolene moieties is not possible anymore, these sulfur-containing molecules might still interact strongly through lateral $\mathrm{S} \cdots \mathrm{S}$ intermolecular contacts. These lateral interactions are of paramount importance in the field of molecular conductors such as TMTTF $^{65}$ and BEDT-TTF salts ${ }^{66}$ since they allow for lateral interactions between conducting stacks and therefore control the degree of delocalization between stacks, up to a point where truly two-dimensional (2-D) electronic structures are found. ${ }^{67}$ The setting of such 2-D structures with their associated closed Fermi surfaces completely suppresses the Peierls transition characteristic of 1D systems and a)
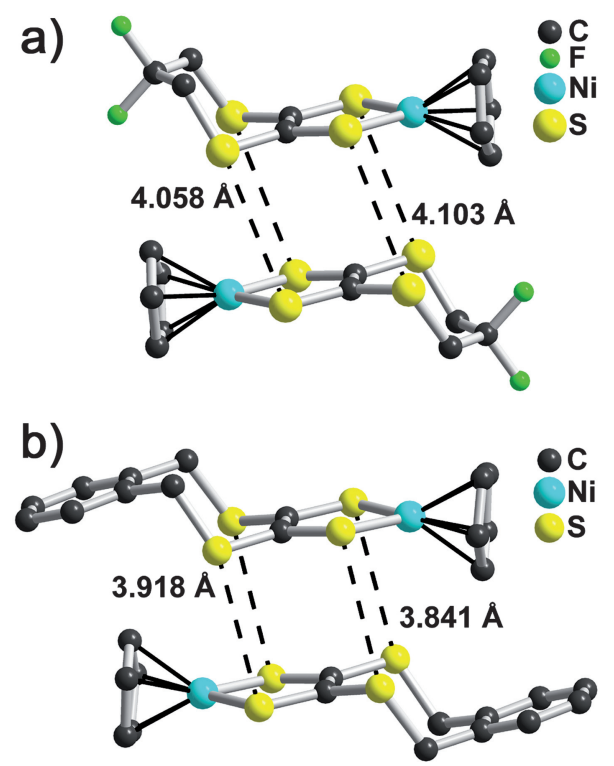

Fig. 3 Dyadic association of $\left[\mathrm{CpNi}\left(\mathrm{F}_{2}\right.\right.$ pddt) $]$ (top) and [CpNi(oxddt)] (bottom). 


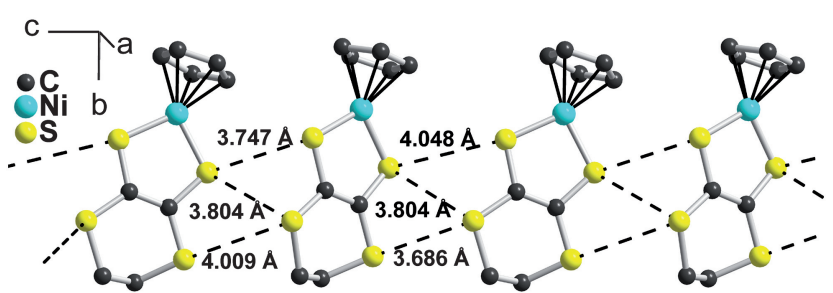

Fig. 4 A view of the alternated spin chain running along $c$ in [CpNi(dddt)].

allows for the apparition of superconductivity in numerous materials, such as those derived from BEDT-TTF, ${ }^{67,68}$ $\left[\mathrm{Ni}(\mathrm{dmit})_{2}\right]$ or $^{69}\left[\mathrm{Ni}(\mathrm{dddt})_{2}\right]$ salts. $^{70} \mathrm{Such}$ lateral $\mathrm{S} \cdots \mathrm{S}$ interactions also develop here in the corresponding radical [ $\mathrm{CpNi}(\mathrm{dddt})]$ and $[\mathrm{CpNi}(\mathrm{dmit})]$ complexes, in their selenium analogues as well as in the benzene tetrathiolate derivative $[\mathrm{CpNi} \text { (bdtodt) }]^{71}$ (Scheme 2$)$. They are all characterized by the presence of chalcogen atoms, not only in the metallacycle as in any $[\mathrm{CpNi}(\mathrm{dt})]$ complex, but also in the fused five- or six-member ring. As shown in Fig. 4, the solid state organization of $[\mathrm{CpNi}(\mathrm{dddt})]$ is dominated by chains running along $c$, with numerous lateral $\mathrm{S} \cdots \mathrm{S}$ contacts between the two

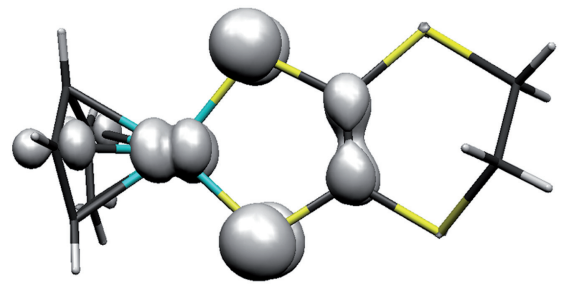

Fig. 5 Spin density distribution in $[\mathrm{CpNi}(\mathrm{dddt})]$. The isodensity surface represented corresponds to a value of $0.005 \mathrm{e}^{-}$ bohr $^{-3}$. crystallographically independent molecules. $^{72}$

This analysis of the solid state organisation was confirmed by the temperature dependence of the magnetic susceptibility, with a susceptibility maximum at $27 \mathrm{~K}$ and a singlet ground state. It was properly fitted by an alternated spin chain model, where the antiferromagnetic interaction within the chain is characterized by two exchange couplings $J$ and $\alpha J$ with $0<\alpha<$ 1 , affording here for [CpNi(dddt)] $J=$ $-45 \mathrm{~cm}^{-1}$ and $\alpha=0.7$. It is important to note here that the spin density distribution calculated for [CpNi(dddt)] (Fig. 5) differs to some extent from that of [CpNi(mnt)] mentioned above. Indeed, sizeable coefficients are now found on the $\mathrm{C}_{2} \mathrm{~S}_{2}$ dithiolene moiety, at the expense of the $\mathrm{Ni}$ atoms and $\mathrm{Cp}$ rings where the spin density decreases, respectively, from 40 and $20 \%$ in $[\mathrm{CpNi}(\mathrm{mnt})]$ down to 30 and $10 \%$ in [CpNi(dddt)].

As shown in Fig. 6, a similar solid state organization with molecules interacting laterally through $\mathrm{S} \cdots \mathrm{S}$ contacts is also found in $[\mathrm{CpNi}(\mathrm{dmit})] .{ }^{43}$ However, these interactions develop not only in one direction but in two, giving rise to a layered structure, with three different interactions, noted a (along $a$ ), $\mathrm{b}$ and $\mathrm{c}$ (along $b$ ) in Fig. 6.

For the purpose of this highlight, all possible exchange interactions in the $[\mathrm{CpNi}(\mathrm{dmit})]$ structure were calculated by exactly the same DFT procedure and computational details employed previously for the [CpNi(mnt)], [CpNi(tfd)] and $[\mathrm{CpNi}(\mathrm{adt})]$ complexes. ${ }^{61}$ The calculated exchange couplings in the layer, $J_{\mathrm{a}}$, $J_{\mathrm{b}}$ and $J_{\mathrm{c}}$ are found, respectively, at -21 , -1 and $-22 \mathrm{~cm}^{-1}$, confirming the presence of two notable antiferromagnetic interactions within the layers through $\mathrm{S} \cdots$ $\mathrm{S}$ contacts. The two relatively strong interactions are ascribed to (i) the large spin density observed in the Mulliken population analysis on the dithiolene moiety, who hosts almost $55 \%$ of the unpaired electron compared to $30 \%$ on the nickel atom and $15 \%$ on the $\mathrm{Cp}$ ring, and (ii) short intermolecular $\mathrm{S} \cdots \mathrm{S}$ distances, between 3.6 and $4.0 \AA$ (for interactions a and c). Just as expected for direct exchange interactions, the coupling constants decrease drastically when the overlap between the dithiolene moieties is weaker, as shown in the comparison of the spin density distributions for interactions $a$ and $b$ in Fig. 7.

The temperature dependence of the magnetic susceptibility of [CpNi(dmit)] indicated large antiferromagnetic interactions, with a Curie-Weiss temperature $\theta_{\text {dmit }}$ of $-66 \mathrm{~K}$ and a susceptibility maximum at $47 \mathrm{~K}^{43}$ Below $20 \mathrm{~K}$, the susceptibility becomes field dependent, the signature of an antiferromagnetic (AF) ground state with $T_{\text {Néel }}=20 \mathrm{~K}$. Since such an ordered state is typically a three-dimensional state, ${ }^{73}$ it can only be understood if a coupling between the magnetic planes exists. A closer inspection of the structure of [CpNi(dmit)] has shown that the outer thiocarbonyl $\mathrm{C}=\mathrm{S}$ group of the dmit ligand points toward the centre of the Cp ring of a neighbouring molecule, located in a parallel plane (Fig. 8). We found that the corresponding calculated exchange coupling $J_{\mathrm{d}}$ amounts here to $-3 \mathrm{~cm}^{-1}$. This interaction is associated to a non-zero spin density on the sulfur atom of the thiocarbonyl group $(5 \%)$ and a sizeable spin density on the $\mathrm{Cp}$ ring $(15 \%)$. Albeit weak, this $J_{\mathrm{d}}$ value is still one tenth of the intra-layer $J$ value while a $10^{-4}$ ratio has been reported to be already sufficient to induce a 3D ordering. ${ }^{74}$ The identification of this
Fig. 6 View of one layer in [CpNi(dmit)] showing the three interactions $(\mathrm{a}, \mathrm{b}, \mathrm{c})$ associated with short $\mathrm{S} \cdots \mathrm{S}$ intermolecular contacts. 
a)

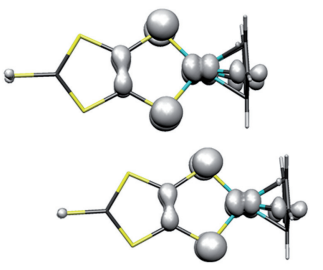

b)

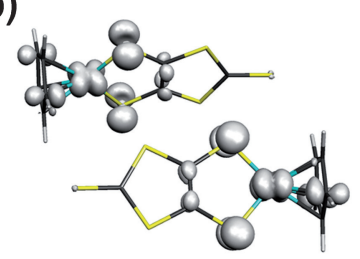

d)

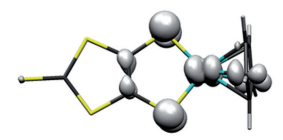

c)
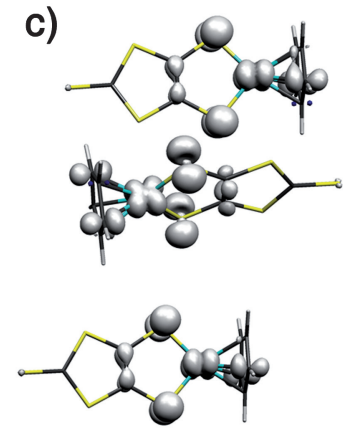

Fig. 7 Spin density distributions in $[\mathrm{CpNi}(\mathrm{dmit})]$ for the calculated interactions in the layers (a, $\mathrm{b}$ and $\mathrm{c}$ ), and the interlayer one (d). The isodensity surface represented corresponds to a value of $0.005 \mathrm{e}^{-}$bohr $^{-3}$.

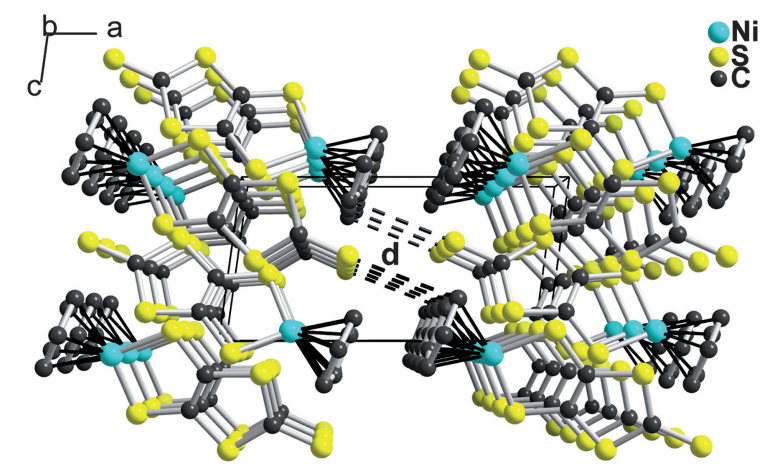

Fig. 8 A view of the unit cell of $[\mathrm{CpNi}(\mathrm{dmit})]$ showing the layered nature and the $\mathrm{C}=\mathrm{S} \cdots \mathrm{Cp}$ interlayer interactions noted (d) in the text (dotted lines).

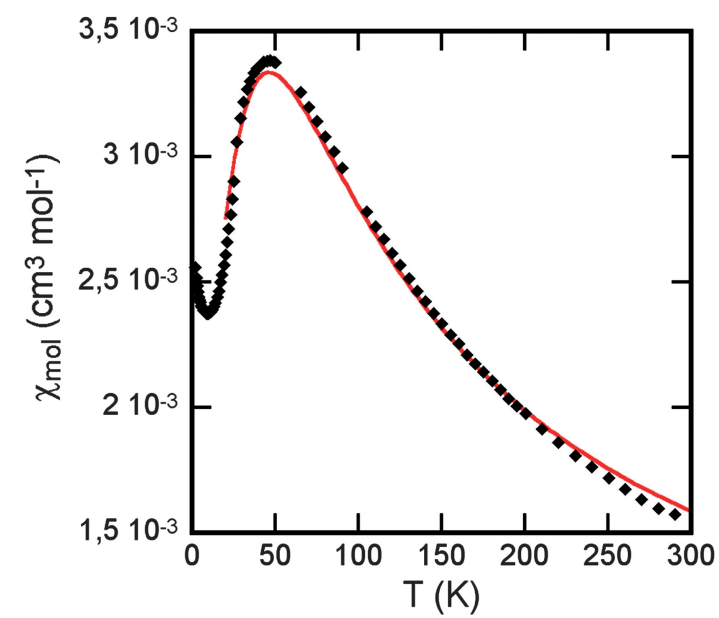

Fig. 9 Temperature dependence of the magnetic susceptibility of [CpNi(dmit)]. The solid line in the high temperature regime (above $T_{\text {Néel) }}$ is a fit to the quadratic layer structure for a $\mathrm{S}=1 / 2$ species (see text).

interaction and the determination of its strength provide now a rationale for the reported antiferromagnetic ground state in $[\mathrm{CpNi}(\mathrm{dmit})]^{43}$

Furthermore, the calculations indicated that within the layers, the radical species are interacting in an almost perfect quadratic layer as the calculated $J_{\mathrm{a}}$ and $J_{\mathrm{c}}$ parameters are essentially identical while $J_{\mathrm{b}}$ is close to zero. In order to test this assumption, the experimental data (Fig. 9) were successfully fitted with the expression reported by Lines $^{73}$ for a $\mathrm{S}=$ $1 / 2$ species in a quadratic layer magnetic structure, together with the contribution of a weak temperature independent paramagnetism $\left(\chi_{0}\right)$, affording $\chi_{0}=5$ $10^{-4} \mathrm{~cm}^{3} \mathrm{~mol}^{-1}$ and $J_{\mathrm{a}}=J_{\mathrm{c}}=-35 \mathrm{~cm}^{-1}$, in agreement with the calculated values $(-22$ $\mathrm{cm}^{-1}$ ) mentioned above.

Thus, the DFT calculations reported here for [CpNi(dmit)] have not only allowed us to fully rationalise its magnetic behaviour but they have also evidenced a very rare example (see below) where a direct interaction between a dithiolene and a $\mathrm{Cp}$ ring is responsible for a sizeable antiferromagnetic interaction, despite the weak spin densities on both this $\mathrm{S}$ atom (5\%) and the $\mathrm{Cp}$ ring (15\%).

\section{Cp $\cdots$ S interactions}

The involvement of the $\mathrm{Cp}$ ring in magnetic interactions is also characteristic of [CpNi(tfd)] where chains of complexes running along $a$ (Fig. 10) are associated with an almost face-to-face interaction between the $\mathrm{Cp}$ and the fluorinated tfd ligand with the shortest $\mathrm{C}_{\mathrm{Cp}} \cdots \mathrm{S}$ intermolecular distances found at 3.767(5) and 3.674(4) А. ${ }^{61}$ In the $b$ direction, molecules alternate in a head-to-tail fashion with the shortest intermolecular $\mathrm{S} \cdots \mathrm{S}$ contact at the long 4.249(1) $\AA$ distance, excluding any sizeable interaction along this direction.

Such description corresponds to a uniform spin chain, as confirmed indeed by the temperature dependence of the magnetic susceptibility. It is characterized indeed by a rounded susceptibility maximum at $40 \mathrm{~K}$ and is properly fitted by an analytical expression given for such Bonner-Fisher systems with $J=-43$ $\mathrm{cm}^{-1}{ }^{61}$ DFT calculations of the corresponding exchange coupling between two molecules give $J_{\text {calc }}=-30 \mathrm{~cm}^{-1}$ and confirm that the face-to-face $\pi-\pi$ type of interaction between a $\mathrm{Cp}$ and dithiolene 


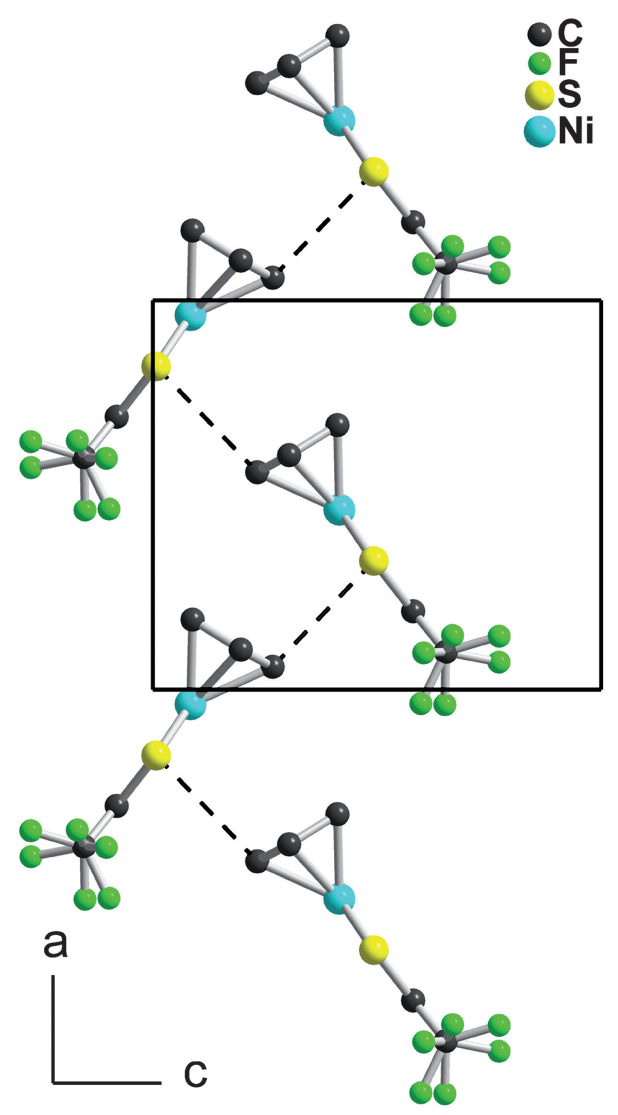

Fig. 10 Projection view of the unit cell of $[\mathrm{CpNi}(\mathrm{tfd})]$ showing the $\mathrm{Cp} / \mathrm{tfd}$ interaction running into chains along $a$. The $\mathrm{CF}_{3}$ groups are disordered in two positions.

moieties is the only interaction responsible for the sizeable antiferromagnetic interaction.

We want to stress here that the ability of the $\mathrm{Cp}$ rings to interact with other's flat systems is not observed in the metallocenes themselves which adopt the socalled "herring-bone" structures with $\mathrm{Cp}$ rings almost perpendicular to each other. ${ }^{75,76}$ Only an electron transfer reaction with acceptor molecules such as TCNE has allowed stacking of the metallocenes, alternating with the $\mathrm{TCNE}^{-}$. radical anions into chains with $\mathrm{Cp} \cdots$ TCNE interactions..$^{27,28}$ In that respect, the originality of the $[\mathrm{CpNi}(\mathrm{dt})]$ radical complexes described here is further illustrated below as direct $\mathrm{Cp} \cdots \mathrm{Cp}$ intermolecular interactions were also identified in several systems.

\section{Direct $\mathrm{Cp} \cdots \mathrm{Cp}$ interactions}

Indeed, The X-ray crystal structures of $[\mathrm{CpNi}(\mathrm{adt})]$ on the one hand, ${ }^{61}$ of $[\mathrm{CpNi}(\mathrm{bdt})]$ on the other hand, ${ }^{72}$ revealed in every complex a face-to-face $\mathrm{Cp} \cdots \mathrm{Cp}$ organization (Fig. 11), besides other short intermolecular contacts. Both complexes are characterized by strong antiferromagnetic interactions, with a singlettriplet behaviour and associated $J_{\exp }$ values of -370 and $-280 \mathrm{~cm}^{-1}$ for [CpNi(adt)] and [CpNi(bdt)], respectively. DFT calculations of all possible exchange coupling pathways between one $[\mathrm{CpNi}(\mathrm{adt})]$ and the neighbouring molecules afforded a $J_{\mathrm{Cp} \cdots \mathrm{Cp}}$ of $-143 \mathrm{~cm}^{-1}$ while all other calculated interactions range between +6 and $-0.6 \mathrm{~cm}^{-1}$, ${ }^{61}$ demonstrating that the $\mathrm{Cp} \cdots \mathrm{Cp}$ face-toface contact is the only interaction at the origin of the strong antiferromagnetic coupling observed in [CpNi(adt)]. Similar calculations for the $\mathrm{Cp} \cdots \mathrm{Cp}$ interaction were also performed on [CpNi(bdt)] and its the selenium analogue, $[\mathrm{CpNi}(\mathrm{bds})] .^{77}$

\section{Spin density distributions}

As mentioned above, the analogous diselenolate derivatives were also investigated in order to experimentally access the spin density distribution in these complexes by EPR through hyperfine coupling with ${ }^{77} \mathrm{Se}$. Natural abundance of ${ }^{77} \mathrm{Se}$ was however not sufficient and the $100 \% \quad{ }^{77} \mathrm{Se}-$ enriched molecular $\left[\mathrm{CpNi}\left({ }^{77} \mathrm{Se}-\mathrm{dsit}\right)\right]$ and $\left[\mathrm{CpNi}\left({ }^{77} \mathrm{Se}-\mathrm{bds}\right)\right]$ complexes (Scheme 4) were prepared and investigated by solution EPR..$^{77}$ Comparison of the experimental ${ }^{77} \mathrm{Se}$ couplings with the atomic constants gave a Se spin density with appreciable p-character $\left(\rho_{\mathrm{p}}\right.$ $=14 \%$ ), which increases to $16 \%$ on the Se atoms of the [CpNi(dsit)] complex. The DFT calculations confirm these results and indicate a larger spin density on the $\mathrm{Cp}$ ring in the bdt/bds system (17-20\%) than in the dmit/dsit one (13-17\%). Using the DFT strategy, different basis sets and functionals were used by Geoffroy to estimate the exchange coupling $J$ values in the bdt and bds complexes. ${ }^{77}$ Note that other experimental approaches to the spin density can be considered, polarised neutron diffraction on the one hand, paramagnetic NMR on the other hand. ${ }^{78}$

It should also be stressed at this point that the dddt and dmit complexes appear indeed to be intrinsically different from most other dithiolene ligands due to their ability to strongly delocalise the spin density on the dithiolene moieties. Indeed, as shown in Table 1, the calculated

Fig. $11 \mathrm{Cp} \cdots \mathrm{Cp}$ interactions in $\mathrm{CpNi}(\mathrm{adt})$ and $\mathrm{CpNi}(\mathrm{bdt})$. 


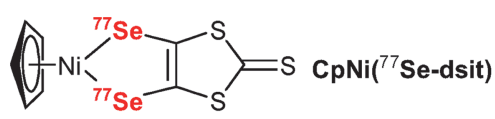

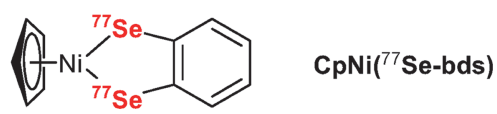

Scheme $4 \quad{ }^{77} \mathrm{Se}$-marked diselenolene complexes.

Table 1 Mulliken spin density distribution in selected [CpNi(dithiolene)] complexes

\begin{tabular}{lllllll}
\hline Complex & Cp & Ni & \multicolumn{4}{l}{$2 \times$ S } \\
\hline CpNi(mnt) & 0.21 & 0.43 & 0.34 & 0.02 & 61 \\
CpNi(tfd) & 0.23 & 0.41 & 0.34 & 0.03 & 61 \\
CpNi(adt) & 0.21 & 0.38 & 0.36 & 0.05 & 61 \\
CpNi(bdt) & 0.21 & 0.42 & 0.32 & 0.05 & 72 \\
CpNi(dmit) & 0.15 & 0.30 & 0.40 & 0.15 & this work \\
CpNi(dddt) & 0.12 & 0.28 & 0.40 & 0.20 & 72 \\
\hline
\end{tabular}

Mulliken spin density distribution shows larger fractions of the spin density on the sulfur atoms than in the other complexes, while the tfd or bdt complexes, for example, are characterised by a spin density fraction on the $\mathrm{Cp}$ ring as high as $23 \%$, which explains that $\mathrm{Cp} \cdots \mathrm{S}$ or $\mathrm{Cp} \cdots$ $\mathrm{Cp}$ contacts can be at the origin of strong antiferromagnetic interactions. For example, in the $\mathrm{CpNi}(\mathrm{bdt})$ or $\mathrm{CpNi}(\mathrm{adt})$ complexes, a direct $\mathrm{Cp} \cdots \mathrm{Cp}$ overlap combined with a large spin density on the $\mathrm{Cp}$ ring are clearly responsible for the strong antiferromagnetic interaction revealed by the temperature dependence of the magnetic susceptibility.

As already mentioned above, this behaviour contrasts strongly with that of the paramagnetic neutral metallocenes

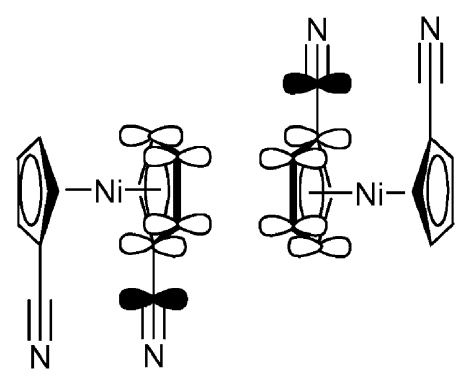

Scheme 5 Spin densities at the carbon atoms of the adjacent cyanocyclopentadienyl ligands of two stacked nickelocenes. The positive and negative spin densities are white and black, respectively (adapted from ref. 79). which do not exhibit such direct $\mathrm{Cp} \cdots \mathrm{Cp}$ overlap. ${ }^{75,76}$ Of a particular note in that respect are the cyanocyclopentadienyl nickelocene and cobaltocene derivatives ${ }^{79}$ $\left[(\mathrm{CpCN})_{2} \mathrm{Ni}\right]$ and $\left[(\mathrm{CpCN})_{2} \mathrm{Co}\right]$ recently reported by Köhler et al. (Scheme 5) where a positive spin density on the $\mathrm{CpCN}$ moiety is associated with a similar face-to-face $(\mathrm{CpCN}) \cdots(\mathrm{CpCN})$ overlap to afford an antiferromagnetic interaction which develops into uniform spin chains with $J=-28$ and $-10 \mathrm{~cm}^{-1}$ for the cyano nickelocene and cobaltocene derivatives, respectively.

\section{Conclusions and perspectives}

We have shown that the extensive series of radical, neutral [CpNi(dithiolene) $]^{*}$ complexes described here offer an invaluable opportunity to evaluate in a precise manner the different paths of magnetic coupling interactions in the solid, as no counter-ion or included solvent are present in these well crystallised, air stable, rigid radical complexes. In most of the examples reported here, the solid state structures adopted by every complex were essentially the result of close packing rules, van der Waals dispersion forces and eventually weak $\mathrm{C}-$ $\mathrm{H} \cdots(\mathrm{N}, \mathrm{O}, \mathrm{S})$ interactions since the various substituents on the dithiolate ligand (thioalkyl, aryl, nitrile, ester, trifluoromethyl, ...) can not be considered as strong "structure-directing" motifs. ${ }^{80}$ In that respect, the crystal engineer has at his disposal many efficient tools such as hydrogen bonding, halogen bonding, segregation of amphiphilic molecules, or chirality to affect and eventually control the solid state organisation. For example, dithiolate ligands functionalised with hydrogen bonding donor ${ }^{81}$ or acceptor groups, ${ }^{82}$ or with chiral substituents ${ }^{83}$ can now be considered for the preparation of the corresponding $[\mathrm{CpNi}(\text { dithiolene })]^{\circ}$ complexes.

Also, these broken symmetry DFT calculations, usually employed for the evaluation of magnetic coupling interactions in polymetallic complexes with spin densities strongly localised on the metal centres, appear as a very useful, cheap and reliable tool for the investigation of such paramagnetic molecular complexes with strongly delocalised spin densities. In the course of our work on the $[\mathrm{CpNi}$ (dithiolene)] series, we have, for the first time, experimentally identified and theoretically confirmed the occurrence of strong antiferromagnetic interactions only attributable to direct $\mathrm{Cp} \cdots \mathrm{Cp}$ overlaps. Their efficiency in these [CpNi(dithiolene)] complexes is rooted here in the large spin density (up to $23 \%$ ) present on the $\mathrm{Cp}$ ring, which endows him with a typical non-innocent character. This attractive peculiarity might not be restricted to these specific series and other complexes ${ }^{79}$ are now worth investigating for this purpose. Another attractive feature related to the non-innocent character of the $\mathrm{Cp}$ ligand is also the predicted possibility of ferromagnetic coupling ${ }^{62}$ through such $\mathrm{Cp} \cdots$ $\mathrm{Cp}$ interactions.

\section{Acknowledgements}

The development of this work has been made possible over the years thanks to a strong collaboration with R. Clérac and C. Coulon at CRRP (Bordeaux, France) and M. Geoffroy at the University of Geneva (Switzerland). They are all warmly thanked for their involvement and friendship. We also thank Eliseo Ruiz (Barcelona) and Olivier Cador (Rennes) for discussions and advice. This project has also been made possible through financial support from CNRS, MENESR and ANR (France), Ministerio de Educación y Ciencia (Spain) through doctoral and postdoctoral fellowships to T.C. and M.N.

\section{References}

1 T. Steiner, Angew. Chem., Int. Ed., 2002, 41, 48.

2 B. Bleaney and K. D. Bowers, Proc. R. Soc. London, Ser. A, 1952, 214, 451.

3 R. J. Bushby, in Magnetism: Molecules to Materials II, ed. J. S. Miller and M. Drillon, Wiley-VCH, Weinheim, 2001, ch. 5. 
4 D. B. Amabilino, J. Veciana, in Magnetism: Molecules to Materials II, ed. J. S. Miller and M. Drillon, Wiley-VCH, Weinheim, 2001, ch. 1

5 B. D. Koivisto and R. G. Hicks, Coord. Chem. Rev., 2005, 249, 2612.

$6 \mathrm{~K}$. Itoh, M. Kinoshita, in Molecular Magnetism, Gordon and Breach Science Publishers, Amsterdam, 2000.

7 (a) K. Mukai, Bull. Chem. Soc. Jpn., 1969, 42, 40; (b) K. Mukai, H. Nishiguc and Y. Deguchi, J. Phys. Soc. Jpn., 1967, 23 125 .

8 K. Boubekeur, J. L. Syssa-Magalé, P. Palvadeau and B. Schöllhorn, Tetrahedron Lett., 2006, 47, 1249.

9 D. B. Amabilino and J. Veciana, Top. Curr. Chem., 2006, 265, 253.

10 M. Tamura, Y. Nakazawa, D. Shiomi, K. Nozawa, Y. Hosokoshi, M. Ishikawa, M. Takahashi and M. Kinoshita, Chem. Phys. Lett., 1991, 186, 401.

11 F. Palacio, G. Antorrena, M. Castro, R. Burriel, J. Rawson, J. N. B. Smith, N. Bricklebank, J. Novoa and C. Ritter, Phys. Rev. Lett., 1997, 79, 2336.

12 O. Kahn, J. Galy, Y. Journaux, J. Jaud and I. Morgenstern-Badarau, J. Am. Chem. Soc., 1982, 104, 2165.

13 O. Kahn, Molecular Magnetism, VCH Publishers, New York, 1993.

14 O. Kahn, Y. Pei, M. Verdaguer, J. P. Renard and J. Sletten, J. Am. Chem. Soc., 1988, 110, 782.

15 S. Ferlay, T. Mallah, R. Ouahes, P. Veillet and M. Verdaguer, Nature, 1995, 378, 701.

16 S. M. Holmes and G. S. Girolami, J. Am. Chem. Soc., 1999, 121, 5593.

17 (a) R. Sessoli, D. Gatteschi, A. Caneschi and M. A. Novak, Nature, 1993, 365, 141; (b) A. Caneschi, D. Gatteschi, R. Sessoli, A. L. Barra, L. C. Brunel and M. Guillot, J. Am. Chem. Soc., 1991, 113, 5873.

18 For a large review, see Single Molecules Magnets and Related Phenomena, SpringerBerlin/Heidelberg, Struct. Bonding, 2006, vol. 122.

19 (a) A. Caneschi, D. Gatteschi, N. Lalioti, C. Sangregorio, R. Sessoli, G. Venturi, A. Vindigni, A. Rettori, M. G. Pini and M. A. Novak, Angew. Chem., Int. Ed., 2001, 40, 1760; (b) R. Clérac, H. Miyasaka, M. Yamashita and C. Coulon, J. Am. Chem. Soc., 2002, 124, 12837; (c) M. Ferbinteanu, H. Miyasaka, W. Wernsdorfer, K. Nakata, K. Sugiura, M. Yamashita, C. Coulon and R. Clérac, J. Am. Chem. Soc., 2005, 127, 3090.

20 C. Coulon, H. Miyasaka and R. Clérac, Struct. Bonding, 2006, 122, 163.

21 G. Aromi and E. K. Brechin, Struct. Bonding, 2006, 122, 1.

22 (a) H. Iwamura, K. Inoue, in Magnetism: Molecules to Materials II, ed. J. S. Miller and M. Drillon, Wiley-VCH, Weinheim, 2001, ch. 2; (b) R. G. Hicks, Angew. Chem., Int. Ed., 2008, 47, 7393.

23 A. Caneschi, D. Gatteschi, N. Lalioti, C. Sangregorio, R. Sessoli, G. Venturi, A. Vindigni, A. Rettori, M. G. Pini and M. A. Novak, Angew. Chem., Int. Ed., 2001, 40, 12760.

24 See also for example: M. Minguet, D. Luneau, E. Lhotel, V. Villar, C. Paulsen, D. B. Amabilino and
J. Veciana, Angew. Chem., Int. Ed., 2002, 41, 586.

25 (a) J. M. Manriquez, G. T. Yee, R. S. McLean, A. J. Epstein and J. S. Miller, Science, 1991, 252, 1415; (b) J. S. Miller and A. J. Epstein, Chem. Commun., 1998, 1319.

26 R. Jain, K. Kabir, J. B. Gilroy, K. A. R. Mitchell, K. C. Wong and R. G. Hicks, Nature, 2007, 445, 291.

27 J. S. Miller, J. C. Calabrese, H. Rommelmann, S. R. Chittipeddi, J. H. Zhang, W. M. Reiff and A. J. Epstein, J. Am. Chem. Soc., 1987, 109, 769 .

28 J. S. Miller, Dalton Trans., 2006, 2742.

29 (a) C. Kollmar and O. Kahn, J. Chem. Phys., 1992, 96, 2988; (b) C. Kollmar, M. Couty and O. Kahn, J. Am. Chem. Soc., 1991, 113, 7994.

30 (a) H. Hilbig and F. H. Köhler, New J. Chem., 2001, 25, 1152; (b) H. Heise, F. H. Köhler and X. Xie, J. Magn. Reson., 2001, 150, 198; (c) I. Gattinger, M. A. Herker, W. Hiller and F. H. Köhler, Inorg. Chem., 1999, 38, 2359; (d) J. Blümel, P. Hofmann and F. H. Köhler, Magn. Reson. Chem., 1993, $31,2$.

31 J. S. Miller and A. J. Epstein, J. Am. Chem. Soc., 1987, 109, 3850.

32 J. B. Goodenough, J. Phys. Chem. Solids, 1958, 6, 287.

33 J. Kanamori, J. Phys. Chem. Solids, 1959, 10, 87.

34 O. Kahn and B. Briat, J. Chem. Soc., Faraday Trans., 1976, 72, 268.

35 J. Cano, P. Alemany, S. Alvarez, M. Verdaguer and E. Ruiz, Chem.-Eur. J., 1998, 4, 476.

36 (a) J. Miralles, O. Castell, R. Caballol and J. P. Malrieu, Chem. Phys., 1993, 172, 33; (b) V. M. Garcia, O. Castell, R. Caballol and J. P. Malrieu, Chem. Phys. Lett., 1995, 238, 222; (c) E. Bordas, R. Caballol, C. de Graaf and J. P. Malrieu, Chem. Phys., 2005, 309, 259; (d) I. Negodaev, C. de Graaf and R. Caballol, Chem. Phys. Lett., 2008, 458, 290.

37 (a) L. Noodleman, J. Chem. Phys., 1981, 74, 5737; (b) L. Noodleman and E. R. Davidson, Chem. Phys., 1986, 109, 131; (c) L. Noodleman and D. A. Case, Adv. Inorg. Chem., 1992, 38, 423.

38 A. D. Becke, J. Chem. Phys., 1993, 98, 5648.

39 E. Ruiz, S. Alvarez, A. Rodríguez-Fortea, P. Alemany, Y. Pouillon, C. Massobrio, in Magnetism: Molecules to Materials, Vol. 2, ed. J. S. Miller and M. Drillon, WileyVCH, Weinheim, 2001, p. 227.

40 (a) E. Ruiz, Struct. Bonding, 2004, 113, 71; (b) E. Ruiz, S. Alvarez, J. Cano and V. Polo, J. Chem. Phys., 2005, 123, 164110; (c) E. Ruiz, T. Cauchy, J. Cano, R. Costa, J. Tercero and S. Alvarez, J. Am. Chem. Soc., 2008, 130, 7420 .

41 (a) R. B. King and M. B. Bisnette, Inorg. Chem., 1967, 6, 469; (b) C. Faulmann, F. Delpech, I. Malfant and P. Cassoux, $J$. Chem. Soc., Dalton Trans., 1996, 2261.

42 M. Nomura, R. Okuyama, C. FujitaTakayama and M. Kajitani, Organometallics, 2005, 24, 5110.

43 M. Fourmigué and N. Avarvari, Dalton Trans., 2005, 1365.
44 U. T. Mueller-Westerhoff, B. Vance, in Comprehensive Coordination Chemistry, ed. Sr G. Wilkinson, Pergamon, Oxford, 1987 ch. 16.5

45 Dithiolene Chemistry, ed. E. I. Stiefel, Prog. Inorg. Chem.. vol. 52, 2004

46 (a) R.-M. Olk, B. Olk, W. Dietzsch, R. Kirmse and E. Hoyer, Coord. Chem. Rev., 1992, 117, 99; (b) P. Cassoux, L. Valade, H. Kobayashi, A. Kobayashi, R. A. Clarck and A. E. Underhill, Coord. Chem. Rev., 1991, 110, 115.

47 (a) P. Zanello, E. Grigiotti, in Trends in Molecular Electrochemistry, ed. A. J. L. Pombeiro and C. Amatore, Marcel Dekker Inc., New York, 2004, Chapter 1; (b) K. Wang, Prog. Inorg. Chem., 2004, 52, 267.

48 (a) P. I. Clemenson, Coord. Chem. Rev., 1990, 106, 171; (b) N. Robertson and L. Cronin, Coord. Chem. Rev., 2002, 227, 93.

49 C. Faulmann and P. Cassoux, Prog. Inorg. Chem., 2004, 52, 399.

50 R. Kato, Chem. Rev., 2004, 104, 5319.

51 M. L. Kirk, R. L. McNaughton and M. E. Helton, Prog. Inorg. Chem., 2004, 52, 111.

52 M.-H. Whangbo, J. M. Williams, P. C. W. Leung, M. A. Beno, T. J. Emge and H. H. Wang, Inorg. Chem., 1985, 24, 3500 .

53 E. Canadell, Coord. Chem. Rev., 1999, 185186, 629.

54 (a) M. Fourmigué and J. N. Bertran, Chem. Commun., 2000, 2111; (b) M. Fourmigué, C. Mézière and S. Dolou, Cryst. Growth Des., 2003, 3, 805.

55 P. Pincus, Solid State Commun., 1972, 11, 305.

56 In ref 13 , chapter 8.

57 M. Fourmigué, Coord. Chem. Rev., 1998, 178-180, 823

58 M. Fourmigué, Acc. Chem. Res., 2004, 37, 179.

59 (a) R. Clérac, M. Fourmigué, J. Gaultier, Y. Barrans, P. A. Albouy and C. Coulon, Eur. Phys. J. B, 1999, 9, 431; (b) R. Clérac, M. Fourmigué and C. Coulon, J. Solid State Chem., 2001, 159, 413; (c) B. Domercq, C. Coulon and M. Fourmigué, Inorg. Chem., 2001, 40, 371; (d) M. Fourmigué, B. Domercq, I. V. Jourdain, P. Molinié, F. Guyon and J. Amaudrut, Chem.-Eur. J., 1998, 4, 1714; (e) M. Fourmigué, C. Lenoir, C. Coulon, F. Guyon and J. Amaudrut, Inorg. Chem., 1995, 34, 4979.

60 (a) M. Fourmigué and C. Coulon, $A d v$. Mater., 1994, 6, 948; (b) B. Domercq, C. Coulon, P. Feneyrou, V. Dentan, P. Robin and M. Fourmigué, Adv. Funct. Mater., 2002, 12, 359.

61 T. Cauchy, E. Ruiz, O. Jeannin, M. Nomura and M. Fourmigué, Chem.Eur. J., 2007, 13, 8858.

62 M. Nomura, M. Geoffroy, P. Adkine and M. Fourmigué, Eur. J. Inorg. Chem., 2006, 5012.

63 M. Nomura and M. Fourmigué, New J. Chem., 2007, 31, 528.

64 The expression used for the Heisenberg Hamiltonian is $\hat{H}=-J \hat{S}_{1} \hat{S}_{2}$ for all exchange interactions discussed in this article.

65 D. Jérome, Chem. Rev., 2004, 104, 5565. 
66 (a) R. P. Shibaeva and E. B. Yagubski, Chem. Rev., 2004, 104, 5347; (b) H. Kobayashi, H. B. Cui and A. Kobayashi, Chem. Rev., 2004, 104, 5243.

67 R. Rousseau, M. Gener and E. Canadell, Adv. Funct. Mater., 2004, 14, 201.

$68 \mathrm{M}$. Tokumoto, in The Physics and Chemistry of Organic Superconductors, Springer Proceedings in Physics 51, ed. G. Saito and S. Kagoshima, Springer VerlagBerlin/Heidelberg, 1990, pp 116-121.

69 E. Canadell, Coord. Chem. Rev., 1999, 1856, 629.

70 A. I. Kotov, L. I. Buravov, E. B. Yagubskii, S. S. Khasanov, L. V. Zorina, R. P. Shibaeva and E. Canadell, Synth. Met., 2001, 124, 357.

$71 \mathrm{M}$. Nomura and M. Fourmigué, $J$. Organomet. Chem., 2007, 692, 2491.

72 M. Nomura, T. Cauchy, M. Geoffroy, P. Adkine and M. Fourmigué, Inorg. Chem., 2006, 45, 8194.
73 M. E. Lines, J. Phys. Chem. Solids, 1970,31, 101.

74 S. T. Bramwell, P. C. W. Holdswoth and M. T. Hutchings, J. Phys. Soc. Jpn., 1995, 64, 3066.

75 (a) W. Bander and E. Weiss, J. Organomet. Chem., 1975, 92, 65; (b) P. Sailer and J. P. Dunitz, Acta. Crystallogr., Sect. B, 1980, 36, 2255; (c) R. D. Rogers, J. L. Atwood, D. Foust and M. D. Rausch, J. Cryst. Mol. Struct., 1981, 11, 183; (d) K. R. Flower and P. B. Hitchcock, J. Organomet. Chem., 1996, 507, 275; (e) A. Avdeef, K. N. Raymond, K. O. Hodgson and A. Zalkin, Inorg. Chem., 1976, 15, 1083; $(f)$ E. O. Fischer, H. P. Fritz, J. Manchot, E. Priebe and R. Schneider, Chem. Ber., 1963, 96, 1418; (g) G. Engbertson and R. E. Rundle, J. Am. Chem. Soc., 1963, 85, 481.

76 D. Braga and F. Grepioni, Organometallics, 1992, 11, 711.
77 P. Grosshans, P. Adkine, H. Sidorenkova, M. Nomura, M. Fourmigué and M. Geoffroy, J. Phys. Chem. A, 2008, 112, 4067.

78 F. H. Köhler, in Magnetism: Molecules to Materials I, J. S. Miller, M. Drillon, ed. Wiley-VCH, Weinheim, 2001, ch. 12.

79 S. Altmannshofer, E. Herdtweck, F. H. Köhler, R. Miller, R. Mölle, E.W. Scheidt, W. Scherer and C. Train, Chem.-Eur. J., 2008, 14, 8013.

80 (a) G. R. Desiraju, Angew. Chem., Int. Ed. Engl., 1995, 34, 2311; (b) G. R. Desiraju, Chem. Commun., 1997, 1475.

81 S. A. Baudron, N. Avarvari and P. Batail, Inorg. Chem., 2005, 44, 3380.

82 M. Fourmigué, C. Mézière and S. Dolou, Cryst. Growth Des., 2003, 3, 805.

$83 \mathrm{H}$. Kisch, B. Eisen, R. Dinnebier, K. Shankland, W. I. F. David and F. Knoch, Chem.-Eur. J., 2001, 7, 738. 